\title{
Symptom shift in 200 patients with H63D syndrome associated with abnormal TCS findings in substantia nigra
}

Dr. Carolina Diamandis ${ }^{1}$, David Seideman ${ }^{1}$, Jacob S Adams ${ }^{1}$, Riku Honda ${ }^{1}$, Marianne Kaufmann ${ }^{1}$, and Lucas Smith ${ }^{1}$

${ }^{1}$ Affiliation not available

May 26, 2021

\begin{abstract}
In a study on the prevention of injury in patients with H63D syndrome and cataplexy, statistical analysis revealed an unexpected but clinically highly significant finding. Apparently, in this patient population, an inverse correlation exists between the severity of tic symptomatology on the one hand and narcolepsy with cataplexy on the other hand, as well as a parallel increase in the typical signs of degeneration observed in transcranial sonography of the substantia nigra. This finding has clinically far-reaching implications.
\end{abstract}

\section{Hosted file}

H63D tics become narcolepsy.pdf available at https://authorea.com/users/410930/articles/ 523720-symptom-shift-in-200-patients-with-h63d-syndrome-associated-with-abnormal-tcsfindings-in-substantia-nigra 